\title{
Wound Healing Activity of the Formulated Silver Chitosan Nanocomposite Cream against Alloxan-Induced Diabetic Wounded Animal Model
}

\author{
Cecilia DS*, Jan Karlo TE, Ashley Marrion CA, Euriel Jasmin PC, \\ Ariza RG, Carmela Ann BL, Althea VS and Celine AAAV \\ School of Pharmacy, Centro Escolar University, Philippines \\ ${ }^{*}$ Corresponding author: Cecilia D Santiago, School of Pharmacy, Centro Escolar \\ University, Manila, Philippines, Tel: +63 2 736.2995; Email: cdsantiago@ceu.edu.ph
}

\begin{tabular}{c}
\hline Research Article \\
Volume 2 Issue 3 \\
Received Date: September 19, 2018 \\
Published Date: October 23, 2018 \\
\hline
\end{tabular}

\begin{abstract}
In the Philippines, the prevalence rate of diabetes is predicted to increase continuously making Filipinos more susceptible to diseases related to the disease above. Drug delivery system using nanotechnology has played a role in the formulation strategy to improve the therapeutic action. This technology offers the advantages of increased stability, enhanced in-vitro antibacterial property, variation in drug solubility and enhanced drug delivery to the action site. This research focuses on the formulation of Silver Chitosan Nanocomposite (SCN) Cream and its use as a wound healing agent using Alloxan Induced Animal Model. SCN with different concentration is developed and is characterized using the following parameters: (i) Transmission Electron Microscopy and (ii) Antibacterial assay. Optimized SCN is formulated into a cream and analyzed based on the following assay including (i) Viscosity test, (ii) Dermal irritation test and (iii) Histopathological evaluation of the wound healing property. The Optimized SCN cream (30\% SCN) has exhibited antibacterial and wound healing property comparable to the silver sulfadiazine cream in treating the wound in diabetic patients in terms of epithelial formation.
\end{abstract}

Keywords: Chitosan; Nanoparticles; Nanotechnology; Wound Healing; Drug delivery; Diabetes

\section{Introduction}

Diabetes is the state in which the body has trouble regulating the blood glucose or blood sugar level which can damage body's system like blood vessels and nerves because the body's cells do not respond appropriately to insulin or there is a deficiency in the production of insulin by the pancreas. Ulceration and infection, which could lead to amputation, are among the several complications observed with diabetic patients that have foot ulcers as the most common wound. There have been studies for the usage of biomaterials and other developmental medicine for the restoration or treatment of damaged cells in the skin. Such biomaterials can be synthetic or natural; examples of natural materials include polypeptides, hydroxyapatites, hyaluronan, glycosaminoglycans (GAG), fibronectin, collagen, and chitosan [1]. 


\section{Open Access Journal of Pharmaceutical Research}

Nanoparticles are the new trend in the pharmaceutical and biomedical fields. These particulate systems have been used as a physical approach to change and improve the pharmacokinetic and pharmacodynamic properties of different types of drugs. Drug articles delivered via nanotechnology has proven the following advantages: (i) high stability (ii) high carrier capacity, (iii) feasibility of incorporation of both substances which are hydrophilic and hydrophobic; and (iv) the feasibility of variable routes of administration are among the vital technological nano particle benefits as drug carriers [2].

In this study, optimized SCN silver is formulated as a cream for enhanced absorption and delivery. The preformulated cream was assessed using various physicochemical, instrumental, microbiological and histopathological assays.

\section{Methodology}

\section{Materials}

Chitosan used as substrate was requisitioned from Sigma Aldrich. All other ingredients used in the study were provided by Centro Escolar University (CEU, Manila). All solvents and reagents used are of analytical grade, except when otherwise specified.

\section{Preparation of Silver Chitosan Nanocomposite}

An aqueous silver nitrate solution $(0.012 \mathrm{~g} / \mathrm{mL})$ was mixed to the $1 \%$ chitosan solution in a beaker $(1: 5)$ and was homogenized for 10 minutes; the resulting solution was added with glucose with continuous stirring for 10 minutes. Five (5) moles of $\mathrm{NaOH}$ was added to the solution and mixed for 25 minutes, resulting to discoloration of the solution. $35 \mathrm{~mL}$ of chitosan $(1 \% \mathrm{v} / \mathrm{v})$ was added until complete dissolution to form silverchitosan nanocomposite [3].

\section{Characterization of Silver Chitosan Nanocomposite}

Transmission electron microscopy: Transmission Electron Microscopy (TEM) JEM-2100F together with Energy-Dispersive X-ray Spectroscopy was employed in the imaging and elemental composition determination of the particles. The sample was placed on a specimen holder grid made up of copper.

Determination of the Antibacterial Activity of Silver-Chitosan Nanocomposite: Three different concentrations $(30 \%, 35 \%$, and $40 \%)$ of the SCN are subjected to agar well diffusion assay. The test organisms:
Staphylococcus aureus and Escherichia coli were inoculated using a sterile cotton swab then streaked over the surface of the prepared agar plates. The zones of inhibition were measured, and the following numerical scale was used to interpret the result [4] (Table 1).

\begin{tabular}{|c|c|}
\hline Zone of Inhibition & Interpretation \\
\hline$>19 \mathrm{~mm}$ & Very Active \\
\hline $14 \mathrm{~mm}-19 \mathrm{~mm}$ & Active \\
\hline $10 \mathrm{~mm}-13 \mathrm{~mm}$ & Partially Active \\
\hline$<10 \mathrm{~mm}$ & Inactive \\
\hline
\end{tabular}

Table 1: Measured with numerical scale.

\section{Formulation and Characterization of Silver- Chitosan Nanocomposite Cream}

Silver-Chitosan Nanocomposite: Preoptimization of the modified fusion method was done to formulate the SNC cream. A component including stearic acid, myristic acid, cetyl alcohol, Caprylic/ capric triglyceride, and isopropyl myristate was dissolved at $75^{\circ} \mathrm{C}$. The preformulated cream are incorporated with deionized water, propylene glycol, $20 \% \mathrm{NaOH}$ and $20 \% \mathrm{KOH}$ and. The cream was then cooled down and was incorporated with Germaben and fragrance with continuous stirring.

\section{Characterization of the Silver-Chitosan Nanocomposite Cream}

Viscosity: The viscosity of the cream was evaluated using a Brookfield viscometer equipped with the spindle number 4 . The characterization was carried out at ambient temperature.

\section{Determination of wound healing activity of the Silver-Chitosan nanocomposite cream through biological evaluation}

Preparation of test animals: A total of pre-weighed and acclimatized male Sprague-Dawley rats were used for the analysis of the wound healing process. The rats have been grouped into three (3) groups (Negative Control Group, Positive Control Group, and SCN cream Group).

Test animals were administered via intraperitoneal route with Alloxan $(125 \mathrm{mg} / \mathrm{kg})$ to induce diabetes. Incision using the scalpel in the veins of the rat's tail was done three days and five days after the administration of Alloxan. The concentration of blood glucose was checked and recorded daily. In this study, rats with glucose levels above the range of $50-135 \mathrm{mg} / \mathrm{dL}$ or $200 \mathrm{mg} / \mathrm{dL}$ were classified as diabetic. 
Prior to the wound healing process, excision wound models were prepared. Using a sterile surgical blade, an area of about half an inch ( 0.5 inches) was cut cautiously on the dorsal part of the rat. Vernier caliper was used to trace the wound size. In the negative control group, diabetic rats are wounded, and no medical treatment was given. For the positive control group, the wounded diabetic rats were treated with the standard drug (silver sulfadiazine cream). And for the experimental group, the wounded diabetic rats were treated with the $30 \%$ SCN Cream. Wounds were checked, and measurements in wound area changes were done on a regular basis. The comparison of the healed wound area on noticed dates with a healed wound area of the control group is significant. The whole process of wound healing is inspected up to epithelialization period and scarring.

Dermal irritation test: The selected group of test animal composed of 3 rats were shaved, specifically the skin lateral to the spinal groove. The sample was applied on the skin, and the selected animal was left undisturbed for
24 to 72 hours. The skin reaction of test animal chosen was evaluated and recorded [5].

Histopathological evaluation: The animal models were subjected to histopathological evaluation; two rats from each group are assessed for histopathological evaluation on the 3rd, 6th and 9th day of the wound healing process. Cross-sectional full-thickness skin specimen's tube was collected for the histopathological alterations [6].

\section{Results and Discussions}

\section{Characterization using Transmission Electron Microscope and Energy Dispersive X-ray Spectroscopy}

The representative TEM images showed that the nanoparticles produced were spherical. The average diameter particle size of the counted 330 particles in the representative micrographs taken at 80,000x magnification was determined to be $7.58 \mathrm{~nm}$ (Figure 1).
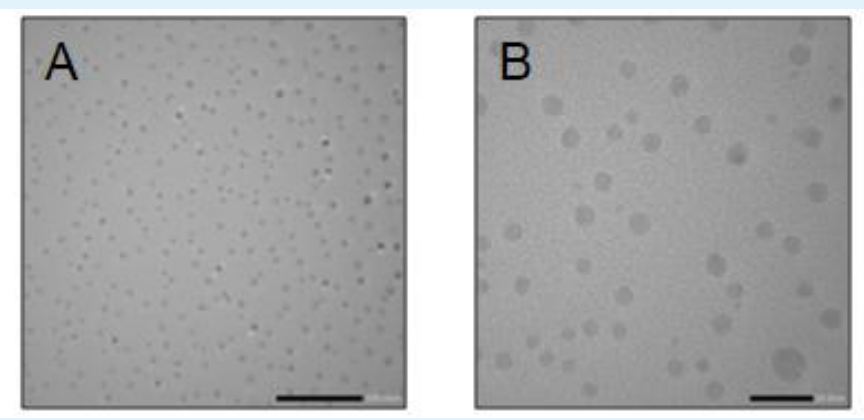

Figure 1: TEM images of the synthesized nanoparticles taken at (A) 80,000x and (B) 300,00x magnification.

The Energy Dispersive X-ray Spectroscopy (EDS) analysis spectra (Figure 2) shows the elemental composition of the representative image stating it was composed mostly of the elements in Table 2 . It proves that the analyzed sample contains chitosan, which is made up mostly of carbon, and silver particles. The specimen grid used in the TEM analysis was made up of copper $(\mathrm{Cu})$ thus giving a $29.4 \%$.

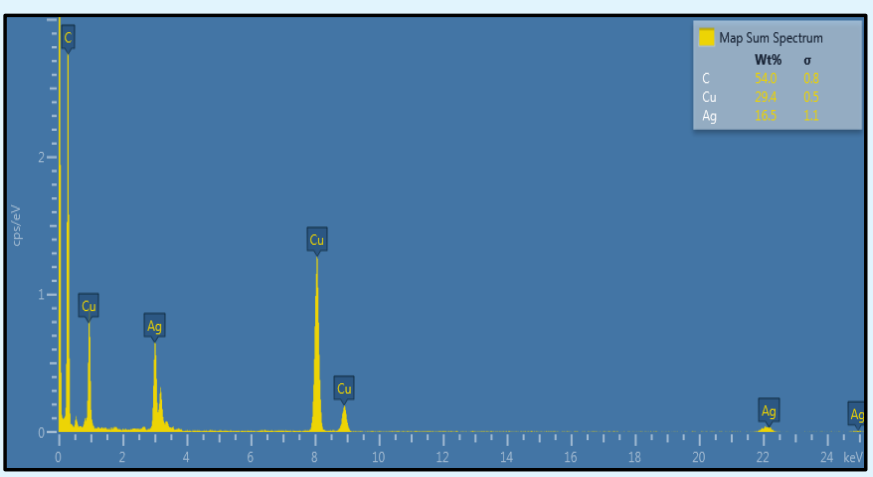

Figure 2: EDS elemental analysis of the representative image. 


\section{Open Access Journal of Pharmaceutical Research}

\begin{tabular}{|c|c|}
\hline Element & Wt\% \\
\hline $\mathrm{C}$ & 54 \\
\hline $\mathrm{Cu}$ & 29.4 \\
\hline $\mathrm{Ag}$ & 16.5 \\
\hline
\end{tabular}

Table 2: EDS elemental composition.

\section{Results of the Antibacterial Activity of the Ag-Cs Nanocomposite}

Table 3 shows that the different concentrations of Ag-
Cs nanocomposite have a higher mean zone of inhibition on Staphylococcus aureus as compared to the positive control. Moreover, each concentration of Ag-Cs nanocomposite has a significant difference between the positive and the negative control in terms of their observed zone of inhibition on Staphylococcus aureus. The results also imply that there is no significant difference among the different concentrations of Ag-Cs nanocomposite in terms of the zone of inhibition observed on Staphylococcus aureus.

\begin{tabular}{|c|c|c|c|c|c|c|c|}
\hline Variable & Compared Groups & $\begin{array}{l}\text { Mean } \\
(\mathrm{mm})\end{array}$ & $\begin{array}{c}\text { Standard } \\
\text { Deviation }\end{array}$ & $\begin{array}{c}\text { Test } \\
\text { Statistic }\end{array}$ & Significance & Interpretation & Remarks \\
\hline \multirow{8}{*}{$\begin{array}{l}\text { Zone of } \\
\text { nhibition }\end{array}$} & Positive Control & 16.90 & 0.00 & $\mathrm{t}=0.00$ & $P=0.0000$ & significantly different & vs. Negative Control \\
\hline & \multirow{2}{*}{\begin{tabular}{|c|} 
Silver Chitosan \\
Nanocomposite $(30 \%)$ \\
\end{tabular}} & \multirow{2}{*}{22.60} & \multirow{2}{*}{0.59} & $t=16.75$ & $\mathrm{P}=0.0001$ & significantly different & vs. Positive Control \\
\hline & & & & $t=66.40$ & $P=0.0000$ & significantly different & vs. Negative Control \\
\hline & \multirow{2}{*}{$\begin{array}{c}\text { Silver Chitosan } \\
\text { Nanocomposite (35\%) } \\
\end{array}$} & \multirow{2}{*}{22.76} & \multirow{2}{*}{2.36} & $\mathrm{t}=4.29$ & $\mathrm{P}=0.0128$ & significantly different & vs. Positive Control \\
\hline & & & & $t=16.66$ & $\mathrm{P}=0$. & significantly different & vs. Negative Control \\
\hline & \multirow{2}{*}{$\begin{array}{c}\text { Silver Chitosan } \\
\text { Nanocomposite (40\%) }\end{array}$} & \multirow{2}{*}{22.98} & \multirow{2}{*}{1.69} & $t=6.23$ & $\mathrm{P}=0.0034$ & significa & vs. Positive \\
\hline & & & & $t=23.56$ & $\mathrm{P}=0.0000$ & significantly c & vs. Negative Control \\
\hline & \begin{tabular}{|c|} 
Silver Nanoparticles \\
$(50 \mu \mathrm{l}$ vs. $70 \mu \mathrm{l}$ vs.100 \\
$\mu \mathrm{l})$
\end{tabular} & - & - & $F=0.04$ & $\mathrm{P}=0.9643>$ & \begin{tabular}{|c|} 
There is NO significant \\
difference between the \\
treatments.
\end{tabular} & - \\
\hline
\end{tabular}

Table 3: Results Obtained from the Comparison of Zone of Inhibition between the Positive Control and Ag-Cs nanocomposite on Staphylococcus aureus.

Table 4 shows that the different concentrations of AgCs Nanocomposite also have a higher mean zone of inhibition on Escherichia coli as compared to the positive control. Moreover, each concentration of Ag-Cs nanocomposite has a significant difference between the positive or the negative control in terms of their observed zone of inhibition on Escherichia coli, except for the 35\% and $40 \%$ concentration compared to positive control. The resulting figures reveal that both $35 \%$ and
$40 \%$ concentrations have no significant difference in the positive control. The results also implied that there is no significant difference among the different concentrations of Ag-Cs nanocomposite in terms of the zone of inhibition observed on Escherichia coli.

The researchers used the $30 \%$ concentration of Ag-Cs nanocomposite to formulate a cream since it showed potential antibacterial activity.

\begin{tabular}{|c|c|c|c|c|c|c|}
\hline Variable & Compared Groups & Mean & $\begin{array}{l}\text { Standard } \\
\text { Deviation }\end{array}$ & $\begin{array}{c}\text { Test } \\
\text { Statistic }\end{array}$ & Significance & Interpretation \\
\hline \multirow{8}{*}{$\begin{array}{l}\text { Zone of } \\
\text { inhibition }\end{array}$} & Positive Control & 13.83 & 0.00 & $\mathrm{t}=0.00$ & $\mathrm{P}=0.0000$ & significantly different \\
\hline & \multirow{2}{*}{$\begin{array}{c}\text { Silver Chitosan } \\
\text { Nanocomposite (30\%) }\end{array}$} & \multirow{2}{*}{22.36} & \multirow{2}{*}{3.19} & $t=10.65$ & $\mathrm{P}=0.0004$ & significantly different \\
\hline & & & & $t=27.90$ & $\mathrm{P}=0.0000$ & significantly different \\
\hline & \multirow{2}{*}{$\begin{array}{c}\text { Silver Chitosan } \\
\text { Nanocomposite }(35 \%)\end{array}$} & \multirow{2}{*}{18.48} & \multirow{2}{*}{3.16} & $t=2.54$ & $\mathrm{P}=0.0639$ & not significantly different \\
\hline & & & & $t=10.11$ & $\mathrm{P}=0.0005$ & significantly different \\
\hline & \multirow{2}{*}{$\begin{array}{c}\text { Silver Chitosan } \\
\text { Nanocomposite }(40 \%) \\
\end{array}$} & \multirow{2}{*}{19.55} & \multirow{2}{*}{3.79} & $t=2.62$ & $P=0.0590$ & not significantly different \\
\hline & & & & $t=8.94$ & $\mathrm{P}=0.0009$ & significantly different \\
\hline & $\begin{array}{l}\text { Silver Nanoparticles } \\
(50 \mu \mathrm{l} \text { vs. } 70 \mu \mathrm{l} \text { vs.100) }\end{array}$ & - & - & $\mathrm{F}=1.38$ & $\begin{aligned} P= & 0.3220> \\
& 0.05\end{aligned}$ & $\begin{array}{l}\text { There is No significant } \\
\text { difference between the } \\
\text { treatments. }\end{array}$ \\
\hline
\end{tabular}

Table 4: Results Obtained from the Comparison of Zone of Inhibition between the Positive Control and Ag-Cs nanocomposite on Escherichia coli. 


\section{Open Access Journal of Pharmaceutical Research}

\section{Formulation and Evaluation of the Silver Chitosan Nanocomposite Cream}

The oil in water cream was white, has a pleasant odor and has no palpable particles.

Viscosity: The cream was subjected to viscosity test using Brookfield viscometer equipped with spindle number 4 . By setting the spindle speed to $20,12,10$, and $5 \mathrm{rpm}$, the researchers obtained 24450, 27300, 28800 and 42400 cps.

The graph showed a curved pattern indicating that as the time increases, viscosity decreases. Generally, the decreased viscosity of the cream was achieved at higher shear rates.

\section{Wound Healing Activity and Dermal Irritation Test of the Ag-Cs nanocomposite Cream}

When the wound-healing activity was examined between the negative control and the Ag-Cs nanocomposite group, the results reflected that on the third day there is a significant difference (with P-value $=0.0052$ and is less than alpha) between the effect of the negative control and the formulated Ag-Cs nanocomposite cream on their wound-healing activity against alloxaninduced diabetic wounded animal model through visual assessment. On the sixth and ninth day, however, the results suggested that there is no more statistically significant difference between the negative control and the Ag-Cs nanocomposite group. This result suggests that the samples were almost all completely healed (Table 5).

\begin{tabular}{|c|c|c|c|c|c|c|c|c|}
\hline Variable & $\begin{array}{l}\text { Teartment } \\
\text { Group }\end{array}$ & Day & Mean & $\begin{array}{l}\text { Standard } \\
\text { Deviation }\end{array}$ & $\begin{array}{c}\text { Test } \\
\text { statistic }\end{array}$ & Significance & Interpretation & Remarks \\
\hline \multirow{9}{*}{$\begin{array}{c}\text { Wound } \\
\text { healing [\% } \\
\text { Difference in } \\
\text { wound } \\
\text { diameter } \\
\text { from Day 1] }\end{array}$} & \multirow{3}{*}{ Negative Control } & Day 3 & 0.63 & 0.11 & $t=-3.56$ & $0.0052^{*}$ & significantly different & \multirow{3}{*}{$\begin{array}{c}\text { vs. Silver } \\
\text { Nanoparticles }\end{array}$} \\
\hline & & Day 6 & 0.63 & 0.30 & $t=-1.02$ & 0.3334 & not significantly different & \\
\hline & & Day 9 & 0.89 & 0.18 & $t=-1.50$ & 0.1635 & not significantly different & \\
\hline & \multirow{3}{*}{ Positive Control } & Day 3 & 0.25 & 0.06 & $t=-0.74$ & 0.4789 & not significantly different & \multirow{3}{*}{$\begin{array}{c}\text { vs. Silver } \\
\text { Nanoparticles }\end{array}$} \\
\hline & & Day 6 & 0.70 & 0.24 & $t=-0.65$ & 0.5294 & not significantly different & \\
\hline & & Day 9 & 0.94 & 0.15 & $t=-1.00$ & 0.3409 & not significantly different & \\
\hline & \multirow{3}{*}{$\begin{array}{l}\text { Silver Chitosan } \\
\text { Nanocomposite }\end{array}$} & Day 3 & 0.29 & 0.12 & & & \multirow{3}{*}{-} & \\
\hline & & Day 6 & 0.78 & 0.18 & & & & \\
\hline & & Day 9 & 1.00 & 0.00 & & & & \\
\hline
\end{tabular}

Table 5: Results Obtained from the Comparison of Effect of Each Treatment in Wound Healing on the third, sixth and ninth day of observation.

Conversely, the wound-healing activity was examined between the positive control and the Ag-Cs nano composite group and the P-values from the result are all greater than alpha $(0.05)$ which means that the null hypothesis is rejected. This implies that at $95 \%$ level of confidence, the researchers interpreted that there is no significant difference between the effect of the positive control and the Ag-Cs nanocomposite group on the wound-healing against Alloxan-induced diabetic wounded animal model using physical evaluation. This further implied that that $\mathrm{Ag}$-Cs nanocomposite group has statistically the same effect as the positive control.

\section{Qualitative Result of the Histopathological Evaluation}

The lesser amount of infiltration of PMNs on the positive and Silver Chitosan nanocomposite group indicates that the inflammation was lesser and was addressed efficiently as compared to the negative; whereas the result on the epithelialization indicates that the negative group has the least rate of epithelium development as compared to the negative and the positive group (Table 6).

\begin{tabular}{|c|c|c|c|}
\hline DAY 3 & Proliferation of PMNs & Proliferation of Fibroblasts & Epithelialization \\
\hline Negative & Mild infiltration & Few proliferation & No epithelial formation \\
\hline Positive & Few Infiltration & Mild to moderate & Epithelium starts to develop \\
\hline SC-NC Cream & Few infiltration & Mild to moderate & Epithelium starts to develop \\
\hline
\end{tabular}

Table 6: Histopathological Result during Day 3. 


\section{Open Access Journal of Pharmaceutical Research}

At day 6 (Table 7), there is still no epithelial formation on the negative group while the epithelium of the positive and the Silver Chitosan Nanocomposite group is still developing.

\begin{tabular}{|c|c|c|c|}
\hline DAY 6 & Proliferation of PMNs & Proliferation of Fibroblasts & Epithelialization \\
\hline Negative & Mild Infiltration & Moderate & No epithelial formation \\
\hline Positive & Few Infiltration & Mild to moderate & Epithelium is still developing \\
\hline SC-NC Cream & Mild Infiltration & Mild to moderate & Epithelium is still developing \\
\hline
\end{tabular}

Table 7: Histopathological Result during Day 6.

At day 9 (Table 8), the epithelium starts to develop in the negative group, while the positive group and silver chitosan nanocomposite group has already shown signs of epithelium development.

Based on the histopathological results, the researchers could infer that for the infiltration of PMNs and proliferation of fibroblast, the positive and the Silver Chitosan nanocomposite group has greater wound healing rate than the negative group whereas, for the epithelial formation, the silver chitosan nanocomposite group obtained the best result.

\begin{tabular}{|c|c|c|c|}
\hline DAY 9 & Proliferation of PMNs & Proliferation of Fibroblasts & Epithelialization \\
\hline Negative & $\begin{array}{c}\text { Mild to moderate infiltration of } \\
\text { PMNs }\end{array}$ & Few Proliferation of Fibroblasts & Epithelium starts to develop \\
\hline Positive & Few infiltration of PMNs & $\begin{array}{l}\text { Mild to Moderate Proliferation of } \\
\text { Fibroblasts }\end{array}$ & Epithelium is still developing \\
\hline $\begin{array}{l}\text { SC-NC } \\
\text { Cream }\end{array}$ & Few Infiltration of PMNs & Mild proliferation of fibroblasts & Epithelium is almost developed \\
\hline
\end{tabular}

Table 8: Histopathological Result during Day 9.

\section{Dermal Irritation Testing}

The 30\% Silver Chitosan Nanocomposite Cream showed no evidence of erythema on the test animal.

\section{Conclusion}

The SCN has exhibited antimicrobial property against test organisms (Staphylococcus aureus and Escherichia coli) used and after formulating into a cream, it proved to be comparable to the silver sulfadiazine cream in treating diabetic wounds using animal models. There is no significant difference in the wound healing activity of the formulated optimized SCN cream and the positive control, silver sulfadiazine cream, against alloxan-induced diabetic wounded animal model using histopathological evaluation.

\section{References}

1. Dieckmann C, Renner R, Milkova L, Simon JC (2010) Regenerative medicine in dermatology: biomaterials, tissue engineering, stem cells, gene transfer and beyond. Exp Dermatol 19(8): 697-706.

2. Gelperina S, Kisich K, Iseman M, and Heifets L (2005)
The Potential Advantages of Nanoparticle Drug Delivery Systems in Chemotherapy of Tuberculosis. Am J Respir Crit Care Med 172(12): 1487-1490.

3. Susilowati E, Triyono, Santosa SJ, Kartini I (2015) Synthesis of Silver Chitosan nanocomposites colloidal by Glucose as Reducing Agent. Indonesian Journal of Chemistry 15(1): 29-35.

4. Honary S, Ghajar K, Khazaeli P, Shalchian P (2011) Preparation, Characterization and Antibacterial Properties of Silver-Nanocomposites using Different Molecular Weight Grades of Chitosan. Tropical Journal of Pharmaceutical Research 10(9): 69-74.

5. Belango Y, Cruz A, Miguel R, Rotairo CR, Oli RA (2016) Anti-inflammatory Property of the Formulated Topical Gel from the Crude Leaf Extracts of Sampaguita (Jasminumsambac L. Family: Oleaceae). International Journal of Chemical Engineering and Applications 7(3): 199-203.

6. Murthy S, Gautam MK, ShaliniGoel, Purohit V, Sharma H, et al. (2013) Evaluation of In Vivo Wound Healing Activity of Bacopamonniera on Different Wound Model in Rats. Bio Med Research International 2013: $1-9$. 
